\title{
Parts of the Whole: Learn More, Learn Better
}

\section{Dorothy Wallace}

Dartmouth College, dorothy.wallace@dartmouth.edu

Follow this and additional works at: https://digitalcommons.usf.edu/numeracy

Part of the Mathematics Commons, and the Science and Mathematics Education Commons

\section{Recommended Citation}

Wallace, Dorothy. "Parts of the Whole: Learn More, Learn Better." Numeracy 5, Iss. 1 (2012): Article 8. DOI: http://dx.doi.org/10.5038/1936-4660.5.1.8 


\title{
Parts of the Whole: Learn More, Learn Better
}

\author{
Abstract \\ Building on previous columns in Numeracy, this column analyzes various teaching techniques in terms of \\ their ability to build cognitive schema, extend existing schema, reinforce learning, move mean \\ understanding of a group of students, and reduce variance in understanding of a group. We offer a \\ pedagogical cycle as an example of how to address multiple learning goals using common teaching \\ methods.

\section{Keywords} \\ pedagogy, learning, evaluation \\ Creative Commons License \\ (c) (1) (8) \\ This work is licensed under a Creative Commons Attribution-Noncommercial 4.0 License

\section{Cover Page Footnote} \\ Dorothy Wallace is a professor of mathematics at Dartmouth. She was 2000 New Hampshire CASE \\ Professor of the Year, and the lead PI of the seminal NSF project, Mathematics Across the Curriculum. \\ She recently finished a text in mathematical biology for first-year students, "Situated Complexity." She was \\ a charter board member of the National Numeracy Network and is now co-editor of this journal.
}




\section{Parts Of The Whole A Column by $\mathrm{D}$. Wallace}

The problem of how best to improve the numeracy of a society is a thorny one, embracing the learning process of a single student but rising in scale to include the management and alteration of an entire system of education. With the issue of quantitative literacy always in mind, this column considers various aspects of the systemic workings of education, the forces acting on classrooms, teachers and students, and mechanisms of both stasis and change.

\section{Learn Better, Learn More}

Like much of mathematics learning, this column builds on previous knowledge. I will be using words, concepts and constructions from earlier pieces to construct a picture of classroom practice from the perspective provided by those columns.

What happens inside a classroom is only a piece of the educational puzzle, but of course it is a critical piece. The teacher, like managers of the system as a whole, is attempting to deal with a population, not a series of individuals. Put in the language of the previous columns, the teacher is attempting to move the average understanding of individuals forward while keeping the variation among them under control, so that the students may continue to be taught as a group. In this column we will look at the details of what goes on in the classroom and offer some preliminary thoughts as to how assorted activities contribute to both ends: improvement of mean understanding and control of variation. These observations are necessarily preliminary because verifying them would require extensive educational research. The author offers them as a starting point in good faith, based on years in the classroom.

Many different kinds of teaching happen in the classroom. The teacher may lecture, meaning that the teacher speaks to the class as a whole for some period of time in order to communicate information or explain a concept. The teacher might lead a discussion about the material. The students may read, alone or out loud to each other, to obtain information. The students may work individually on problems and projects, or they may do so in a group. There may be extensive projects spanning days or weeks. The students might be asked to write about what they have learned.

There are more possibilities, but these offer a starting point for discussion and analysis. Recalling examples discussed earlier ought to remind us that attempting to improve the mean understanding of a group of people and controlling the variation among them are often difficult to accomplish simultaneously. Not surprisingly, some of these techniques are better at accomplishing one of these 
than the other. Similarly, we have seen that cognition is built, loosely speaking, in two directions. Some techniques of teaching lend themselves better to reinforcing a schema by building horizontally on the "cognitive pyramid" and others are more useful in creating new, more advanced schemas, thereby building the pyramid vertically.

\section{Overview of Various Teaching Methods}

\section{Reading}

Reading can be used to obtain factual information, learn relationships between understood phenomena and, occasionally, in the service of constructing new concepts. The last is rare, because without the ability of the reader to question the author and obtain clarification for answers, it is predictably hard to establish a new schema reliably. There is no real check on understanding. As an activity done by a single individual, reading assignments are likely to increase the variation in understanding among students unless followed by group discussion. A second problem with reading is the question of retention. In order to remember something, it must be reinforced, and soon. Psychologists have studied this problem, and report exponential decay of retained material over time. To put it loosely, if one reads a book or article on something and then puts it down and moves on to another activity, within a half an hour of completing it the memory of what was learned begins to evaporate. Within a day, a substantial amount of the learning will be lost. After a week, about half the material will be gone if not reinforced in some way. After six weeks nearly all the learning will be lost if not reinforced. Whatever remains after six weeks is likely to be a long-term gain. Because of the difficulty of retention, the traditional college practice of cramming for an exam results in no real, long-term learning. There is an obvious exception to these remarks, and that is when reading is done in with the goal of becoming a better reader, so that acquisition of any particular content or concept is not the goal.

\section{Lecture}

Verbal communication, as in lecture, is somewhat better for building schema because dialogue with students can establish whether they are progressing, and the lecture can be adjusted (assuming it is live) in speed or level as the state of student knowledge becomes apparent. The issues with retention also plague the lecture and must be addressed if the student is to learn anything in the long run. Psychologists have looked at the attention span of people listening to lectures and have found it to be fairly short. After ten or fifteen minutes the mind of the listener involuntarily wanders. Continuing to lecture past this point is a waste of time. Of course, some people (like professional mathematicians) have a much longer attention span for listening carefully to a lecturer. The author claims 40 minutes as a personal average. Other people (like kindergarteners) have a very 
short attention span. Because of these considerations, the best use of lecture is sparingly, with the goal of quickly moving mean understanding upward. Reinforcement of new understanding by other methods must follow quickly afterwards. To put it pointedly, by the time the student sits down to do homework in the evening, it is already too late. Critical understanding gained in the morning is lost by supper if not reinforced.

Lecture is not good at reducing the variation of understanding within the class. The lecturer cannot control increasing variation in the understanding of the students, because he or she must address the group as a single individual. Every explanation given, every comment, or sentence, presupposes a certain understanding in the mind of the listener. The lecturer speaks to the average student, or the precocious student, or the struggling student, but the lecturer cannot speak to them all at once. Students who are advanced will feel the material is moving slowly and those who are behind may not understand it, thus falling farther behind. From this standpoint, reading is even worse. A reliance on these methods alone allows variance to grow naturally and offers no method for controlling it.

\section{Individual assignments}

Individual work, whether writing about something, solving a problem, or practicing a skill recently acquired, moves mean understanding forward very efficiently. Students have a fairly long attention span for thinking about and solving problems, writing papers, etc, especially compared to their typical response to lecture. Depending on how an assignment is structured, cognition can grow in either direction, although probably not both directions simultaneously. Repeated practice with certain kinds of problems or questions can cement understanding and increase retention of important concepts. Research has shown, however, that more practice is not necessarily better. There is a point at which further practice does not improve understanding any more. For each subject this point needs to be documented, in the interest of using precious time efficiently. Individual work must, necessarily, increase variation. The students progressing more slowly will lag further and further behind the quicker ones, unless something is done to counteract this tendency.

\section{Cooperative learning, or group work}

A highly advertised innovation in teaching at all levels is cooperative learning, or group work. This technique involves giving a small group, (optimally three to five), students an assignment that is sufficiently complicated that they need to work together to complete it. Sometimes the difficulty lies in the mere complexity of the task, requiring the students to break it into smaller tasks, assign jobs to individuals, complete these jobs, report back to the group, synthesize results, etc. Sometimes the difficulty is purely conceptual, asking students to solve a problem that is likely to require many false starts. In this case, the process 
of generating many possible strategies, pointing out why some won't work, following others until they succeed or fail, etc, is a shared responsibility of the group. In some cases, a simulation in the form of a game works well as a cooperative exercise. In all of these examples, the group work is used to solidify a schema. It is very difficult to design group assignments that spontaneously create cognitive dissonance, break open an old schema, and build a new one. Usually that is done with help of the instructor first, after which a cooperative task will be given to strengthen the new schema. Most cooperative assignments build the cognitive pyramid sideways.

A side effect of cooperative learning strategies is the informal tutoring that takes place among students in the group. If the assignment and grading strategy are well designed, it will behoove everyone in the group to make sure everyone else understands what is going on. Members of the group supply each other with the needed tutelage in facts and concepts necessary to the assignment. The individual being tutored feels considerable peer pressure to come up to speed. This pressure is absent from all other kinds of learning, and it is a powerful force. The main criticism students have about these assignments comes from the ones who have mastered more material than their peers. Although they learn things from these assignments and progress in their understanding, they often feel that they could have done just as well by themselves. This sensation is justified, because cooperative learning is one of the few techniques likely to reduce variation among students. A well-designed cooperative learning assignment will not harm the best students, but it will do much to bring the bottom students up to speed.

Because the less-expert students are not isolated from their high-achieving peers, the target for which the lesson is aiming remains high. Peer pressure exerts an added force on these students, and the small group offers considerable tutelage and other intellectual support. Cooperative learning is that rare teaching technique that improves the average understanding of the class by bringing up the bottom of the distribution, without creating multiple tracks. It is a critical tool for managing variation in the classroom.

\section{Student projects}

Long-term, complex projects are ill suited to building vertically on the cognitive pyramid. It is much more likely that they will build sideways, connecting and reinforcing many different kinds of knowledge. These assignments can potentially extend many cognitive structures simultaneously. For example, if a science experiment is well thought out as a lesson, it will include much mathematical analysis and a substantial writing component before it is complete. Three kinds of knowledge are being reinforced and connected in such a lesson. Because of the complexity of the project, it will be difficult to track or control variation among students until after it is over. The advantage of these projects 
(again, if well designed) is their capacity to improve many kinds of understanding at once.

\section{Writing assignments}

Writing assignments cover a wide spectrum of learning. The process of explaining a recently learned concept is very helpful in solidifying that concept in the student's mind. Writing assignments that connect different concepts to each other build cognition horizontally. Writing is usually done individually and will, in and of itself, do little to reduce variation among students, but much to improve mean understanding by improving retention and connections between ideas. For technical subjects involving quantitative information or models or scientific experiments, the process of writing about one's own work appears to improve the ability of students to be critical readers of similar technical literature. Again, this is just the author's own observation based on my own students, and I know of no study attempting to measure how critically students read technical material or how to teach them to do so.

These examples of teaching techniques are but a few of those in use in classrooms. Analyzing them in terms of variation and cognitive growth tells a lot about how they might be used to manage student learning intelligently toward a particular goal. The entire debate about fads in teaching, "educational reform," traditional methods versus new ones, and so forth, comes down to a lack of understanding of what these various methods are best equipped to accomplish. To the extent that these arguments go beyond knee-jerk political rhetoric, they amount to endless comparisons of methods, with the goal of choosing an optimal method to reign in all situations. The phrases "learn better" and "learn more" are ambiguous and misleading, as we have seen in our discussion. There are many ways of learning more, and "better," as applied to a population, cannot be measured by a single number. If we understand what our pedagogical tools can and cannot do, we can make far more efficient use of them. A good carpenter has a lot of tools on hand, and so does a good teacher. What follows is an example of how one might design learning activities to take advantage of the strengths of particular approaches.

\section{The Cycle of Variance}

The handful of teaching techniques, just described, contribute in different ways to raising understanding and controlling variation. On the basis of these observations one can imagine a variety of strategies designed to achieve both ends, depending on a variety of approaches. This chapter offers one suggestion of how to manage lessons on a single topic to this end, but many more paths might lead to the same end. 
Suppose we want to teach a particular math concept, and let us say it is a fairly difficult one. We might begin with a verbal explanation of the basic idea, along with some examples and a chance for students to ask questions. This will move mean understanding rapidly in the direction we want, but the effect will last for only a short time before the students forget.

Hard on the heels of this introduction, we would like to solidify any gain that is made by having students work a few problems that require the new concept. After doing this, there is a better chance that they will retain the material long enough to do a similar problem several hours later. The following day the material is reinforced with a few similar problems, and on the third day the students take a quiz. This quiz is not for the purpose of assigning a grade, but so that the teacher can determine the extent to which understanding varies and the extent to which average understanding in the class has improved.

If there is substantial variation in understanding (and there usually is), the next job is to offer the students activities that will reduce this variation by improving bottom scores. Students can be sorted into groups of high variance based on the quiz, insuring that weak and strong students are in the same group. Groups will be given a fairly complex task that requires using the concept in question. In addition to working together to complete the task, they are told that each student will be tested separately on their understanding, but all students will receive the average grade of everyone in their group. Grade incentives like this one are a well-known method for improving total performance. At the end of the exercise, evaluation should indicate a reduced variation among student performance.

If the variation seems small enough, then it's sufficient merely to reinforce the material now and then with exercises that use it so that it is not lost. These may be "math lessons" or they may happen in the context of other learning. If the variation is still large, another cooperative exercise could be given and the cycle repeated. In fact, even if everyone masters the concept quickly, extra activities are needed for the sake of retention.

The strategy outlined here is not meant to be rigid. It is supposed to point out the possibility of intentionally taking into account both mean and variation by offering a cycle of activities pointed first at one, then the other. The activities would look quite different if, instead of teaching a new concept, one were trying to teach the connections among concepts. The basic cycle would look the same; however, with activities designed to move understanding forward alternating with activities designed to reduce variance by improving the understanding of the ones who had not yet "gotten it." It is important that these second kinds of activities include the quicker students, because reinforcing a concept is as useful as learning it in the first place. The slower students have a chance to improve their understanding of the concept and the quicker students have the opportunity to improve their retention of the concept. Figure 1 pictures a cycle of learning based on these ideas. 


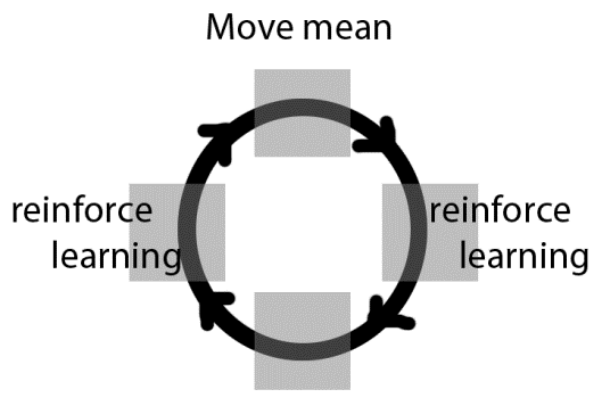

Reduce variance

Figure 1. The cycle of variance

Because numerous activities are required to make a cycle like this work, it is necessary to offer activities that vary enough to keep everyone interested. In later stages of the cycle after an initial gain is made, using an interdisciplinary approach can keep material fresh for everyone. Those who manage the curriculum must see to it that such an approach is feasible for the teacher. The expectation on the part of the teacher must be that everyone will learn the concept.

A cycle of activities can be devised for each concept being taught. It may not be necessary to complete the cycle for one concept before beginning the cycle for another. During a single lesson, students could very well spend two or three distinct activities working on two or three distinct concepts, at a different point in the cycle for each one. Many good teachers instinctively arrange lessons this way, but an intentional, closely monitored approach couldn't hurt matters.

\section{Evaluation}

The idea of measuring student performance at each step, to see if variation is decreasing or if the mean is moving, is no different from Deming's observation that measuring outcome during a process is far more useful than measuring it when the process is complete. Student grades should be based only on measurements taken at the end of a cycle of learning, because until then they are part of the process itself. The point of such evaluation is to monitor the educational process, not the temporary success or failure of the individual. Furthermore, frequent evaluation must be done with a light touch, because evaluation is an observation device that takes its own toll on the system in terms of time, energy, and good will.

Our current attitude toward "high stakes" testing hampers useful formative evaluation that could guide instructors toward better teaching strategies. Of course there need to be occasional summative evaluations of students and schools, 
but for the purposes of teaching and learning it is far more useful to have numerous intermediate, low-stakes evaluations. This is helpful for even the fastest moving students, because what is learned today must be repeated, used, incorporated into multiple schemas, or else it will be lost tomorrow.

The context of this entire discussion presumes that the teacher is attempting to keep a group of students more or less together in their knowledge. Constantly increasing variation makes it difficult to build on prior knowledge, as is typical of a sequence of science courses or the first year in mathematics graduate school. However, it is important to acknowledge that in many instances the natural increase in variation among students is an irrelevant consideration. Sometimes, as in an interdisciplinary course involving math and humanities, or in a topics course that is not the prerequisite for anything, we gladly celebrate the variation of our students. We don't mind that some are better than others, that some excel at certain aspects and are outright bad at other things, that some are fully engaged and others less so. We are satisfied that they are there, and want to learn. In these situations it is appropriate for the basis of evaluation to be improvement rather than an absolute standard.

\section{Last Thoughts}

It is important to appreciate how difficult it is for institutions, departments and individual instructors to achieve clarity about the goals of their courses and needs of their students. Lack of clear goals for a population of students-as opposed to "learning objectives" for individual students-makes it impossible to choose effective pedagogy and evaluation for our classes and institutions. It muddies all discussions of "standards" and "teaching techniques." It prevents the objectives of the instructor from aligning with those of the larger institution.

Whether it is desirable to reduce variation, keep the class together for pedagogical purposes or let knowledge diverge; satisfy some minimum standard or simply move everyone forward; build cognitive schemas or substantially extend them-these are key questions that determine not only the content of a course or a single lesson, but also its pedagogy and its evaluation. 